\title{
Chemical diffusion of fluorine in melts in the system $\mathrm{Na}_{2} \mathrm{O}-\mathrm{Al}_{2} \mathrm{O}_{3}-\mathrm{SiO}_{2}$
}

\author{
Donald B. Dingwell * and Christopher M. Scarfe \\ Experimental Petrology Laboratory, Department of Geology, University of Alberta, Edmonton, Alta. T6G 2E3 (Canada)
}

Received October 25, 1984

Revised version received January 25, 1985

\begin{abstract}
The volatilization of fluorine from three melts in the system $\mathrm{Na}_{2} \mathrm{O}-\mathrm{Al}_{2} \mathrm{O}_{3}-\mathrm{SiO}_{2}$ has been investigated at 1 atm pressure and $1200-1400^{\circ} \mathrm{C}$. The melts chosen have base compositions corresponding to albite, jadeite and a peraluminous melt with 75 mole $\% \mathrm{SiO}_{2}$. Melt spheres were suspended from platinum loops in a vertical tube furnace in a flow of oxygen gas, then quenched, sectioned and analysed by electron microprobe. The microprobe scans indicate that transport of fluorine to the melt-vapor interface is by binary, concentration-independent interdiffusion of fluorine and oxygen. F-O interdiffusivity increases in the order albite < peraluminous < jadeite. There is no simple reciprocal relationship between F-O interdiffusivity and melt viscosity. Comparison with data on high-pressure interdiffusivity of fluorine and oxygen in jadeite melt indicates that F-O interdiffusivity increases with pressure from 0.001 to $10 \mathrm{kbar}$ while the activation energy remains unchanged.

Fluorine chemical diffusivity in albite melt is substantially lower than $\mathrm{H}_{2} \mathrm{O}$ chemical diffusivity in obsidian melts suggesting that different diffusive mechanisms are responsible for the transport of $\mathrm{F}$ and $\mathrm{H}_{2} \mathrm{O}$ in igneous melts. Fluorine diffuses in albite melt via an anionic exchange with oxygen whereas water probably diffuses in obsidian melt via an alkali exchange mechanism.
\end{abstract}

\section{Introduction}

Our understanding of diffusive transport in silicate melts is still very poor. In particular, data on anionic diffusivities is lacking. Investigation of anionic diffusivities in silicate melts is important for a better understanding of the coordination of anions in the melt structure and for calculation of equilibration rates in igneous melts during petrogenesis. Examples of fluorine-rich igneous rocks are widespread [1-5] and their transport properties may be significantly affected by fluorine. For these reasons, the following study was undertaken to investigate the transport of fluorine in silicate melts. The volatilization of fluorine from silicate melts has been investigated by several workers

\footnotetext{
* Present address: Geophysical Laboratory, 2801 Upton St. NW, Washington, D.C., 20008, U.S.A.
}

using weight loss and/or bulk chemical analysis techniques [6-9] and the present study uses the relatively high volatility of fluorine in melts in the $\mathrm{Na}_{2} \mathrm{O}-\mathrm{Al}_{2} \mathrm{O}_{3}-\mathrm{SiO}_{2}$ system to investigate fluorine diffusion in these silicate melts. This system was chosen because the structure and physical properties of melts in the base system has been investigated by various workers [10-14] and the normative compositions of many fluorine-rich igneous melts containing greater than 50 mole $\%$ of feldspars + feldspathoids are well-represented by this system.

\section{Experimental method}

The three melts investigated have fluorine-free compositions corresponding to albite, jadeite and a peraluminous melt with 75 mole $\% \mathrm{SiO}_{2}$. Fluo- 
rine was included in the melt compositions by substituting $2 \mathrm{AlF}_{3}$ for some of the $\mathrm{Al}_{2} \mathrm{O}_{3}$ of the base composition. Thus the substitution is essentially two moles of fluorine for one mole of oxygen, denoted by the exchange operator, $\mathrm{F}_{2} \mathrm{O}_{-1}$. The starting compositions were synthesized from reagent grade sodium carbonate, alumina, aluminum fluoride and purified quartz sand. Carbonate + oxides + fluoride equivalent to a decarbonated weight of 600 grams were mixed thoroughly for 12 hours and then fused in a $10.5 \mathrm{~cm}$ long by $5.5 \mathrm{~cm}$ diameter platinum crucible for 6-10 hours at $1600^{\circ} \mathrm{C}$ to ensure homogeneity and escape of air bubbles.

$\mathrm{Na}, \mathrm{Al}$ and $\mathrm{Si}$ contents of quenched melts (glasses) were determined by energy dispersive analysis using an ARL-SEMQ microprobe fitted with an EEDS-ORTEC energy dispersive system. Operating conditions were a $15 \mathrm{kV}$ accelerating voltage, a 4 nA sample current and 240 second count times. The beam was rastered over a $20 \times 20$ $\mu \mathrm{m}$ area, a technique which proved adequate for avoiding volatilization of $\mathrm{Na}$ or $\mathrm{F}$ during analysis. The homogeneity of each glass was confirmed for $\mathrm{Na}, \mathrm{Al}$ and Si by analysing six spots on each glass.

Fluorine contents of the starting materials were determined by neutron activation analysis. Twelve replicates of each glass were determined against a curve for reagent grade $\mathrm{CaF}_{2}$. The technique was verified with NBS standard glass SRM 91 (5.72 wt.\% F). Fluorine contents were combined with the raw spectra for $\mathrm{Na}, \mathrm{Al}$ and $\mathrm{Si}$ as input for EDATA2 [15] allowing full ZAF reduction of the $\mathrm{Na}, \mathrm{Al}$ and $\mathrm{Si}$ data (Table 1).

\section{TABLE 1}

Analyzed melt compositions ${ }^{\text {a }}$

\begin{tabular}{lrrllll}
\hline & $\mathrm{Na}$ & \multicolumn{1}{c}{$\mathrm{Al}$} & $\mathrm{Si}$ & $\mathrm{F}$ & $\mathrm{O}$ & Total \\
\hline Albite & 8.31 & 9.15 & 31.54 & 5.8 & 44.5 & 99.30 \\
Jadeite & 11.17 & 12.75 & 26.72 & 6.3 & 43.0 & 99.94 \\
Peraluminous & 6.14 & 10.87 & 31.58 & 5.4 & 45.5 & 99.49
\end{tabular}

a $\mathrm{Na}, \mathrm{Al}$ and $\mathrm{Si}$ determined by electron microprobe; $\mathrm{F}$ determined by neutron activation analysis; $O$ by stoichiometry. Errors for microprobe data expressed as percent of the amount present at 3 standard deviations: $\mathrm{Na}(4.3 \%), \mathrm{Al}$ $(2.0 \%)$, Si (1.0\%). Errors in fluorine determinations are \pm 0.1 wt. $\%$ F at 1 standard deviation.
Selected chips of glass were ground into spheres by using the method of Bond [16]. Spheres of glass (4-8 $\mathrm{mm}$ diameter) were suspended from platinum loops in an electrically-heated vertical tube furnace, equipped with a gas-tight alumina muffle tube. An "infinite" $\mathrm{O}_{2}$ gas reservoir was maintained during the experiments by flowing oxygen gas through the furnace at a linear flow rate of $0.10 \mathrm{~cm} / \mathrm{s}$. Temperatures were controlled using a Pt-Pt13Rh thermocouple which was suspended within a few millimeters of each sphere. Three spheres were run at each temperature for each composition. The experiments ranged in duration from 600 to 19,200 seconds and melt spheres were quenched in air by removal from the furnace. Quenched melt (glass) spheres were removed from the ceramic hanger, ground in half, mounted in epoxy and polished for electron microprobe analysis. In rare cases where spheres deformed due to improper loop size or mounting, the runs were discarded. Generally, spherical shape was well-preserved.

Analyses of the concentration profiles resulting from volatilization were performed using an ARL-SEMQ microprobe in the wavelength dispersive mode. Operating conditions for the scans of $\mathrm{Na}, \mathrm{Al}$ and $\mathrm{Si}$ were a $15 \mathrm{kV}$ accelerating voltage and a $4 \mathrm{nA}$ sample current with the beam rastered over a $10 \times 10 \mu \mathrm{m}$ area. Fluorine scans and step analyses required a sample current of $40 \mathrm{nA}$ to achieve reasonable count rates (approximately 40 $\mathrm{cps} / \mathrm{wt} . \% \mathrm{~F}$ ). The quantitative analyses for fluorine were 100 second counts using a rastered beam as for $\mathrm{Na}, \mathrm{Al}$ and $\mathrm{Si}$.

Wavelength dispersive scans for $\mathrm{Na}, \mathrm{Al}, \mathrm{Si}$ and $F$ (Fig. 1) show two basic features. Firstly, the concentration profile of fluorine extends (over several hundred micrometers) from essentially zero concentration at the sphere edge to a plateau corresponding to the original, undepleted fluoride concentration of the melt (Table 1). Secondly, the concentrations of $\mathrm{Na}, \mathrm{Al}$ and $\mathrm{Si}$ are constant over almost the entire length of the fluorine depletion zone except within $30-50 \mu \mathrm{m}$ of the sphere edge.

Quantitative analyses of fluorine content across concentration profiles were obtained by standardization to analyses of the starting glasses. The exchange of up to 5-6 wt.\% $\mathrm{F}$ for $\mathrm{O}$ has an 


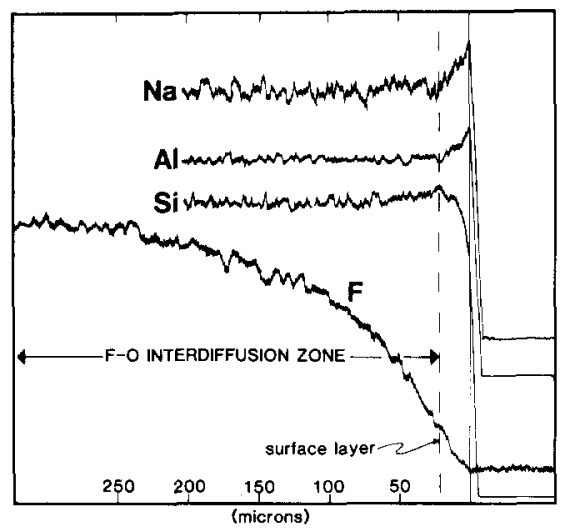

Fig. 1. Concentration profiles of $\mathrm{Na}, \mathrm{Al}, \mathrm{Si}$ and $\mathrm{F}$ produced in an experiment on fluorine-bearing jadeite melt at $1200^{\circ} \mathrm{C}$.

insignificant effect on the fluorine ZAF correction. The 30-50 $\mu \mathrm{m}$ wide "surface layer" of Si depletion and $\mathrm{Na}+\mathrm{Al}$ enrichment (Fig. 1) indicates the escape of fluorine from the melt surface as an Si-bearing gas phase, possibly $\mathrm{SiF}_{4}$ gas. This interpretation is corroborated by previous studies of fluorine volatility in dry systems at 1 atm [6-8].

\section{Data reduction}

The constant levels of $\mathrm{Na}, \mathrm{Al}$ and $\mathrm{Si}$ inside the surface layer mean that bulk diffusion of fluorine to this layer may be treated as binary interdiffusion of fluorine and oxygen, with no net transport of cations. The binary nature of $\mathrm{F}-\mathrm{O}$ interdiffusion has been previously observed in high-pressure diffusion couple experiments [17]. The mathematical treatment of diffusion for these experiments is for a one-dimensional semi-infinite medium [18,pp. 35-38]. The chemical gradient that serves as the driving force for chemical diffusion is quantified by the "reduced concentration" term; $(C-$ $\left.C_{1}\right) /\left(C_{0}-C_{1}\right)$ where $C$ is the measured concentration along the profile, $C_{1}$ is the initial concentration in the melt, and $C_{0}$ is the concentration in the gas phase. This equation holds equally well for the case of absorption into a semi-infinite melt medium from a gas phase (e.g. the hydration experiments of Shaw [19]) as it does for the present case of desorption or volatilization. In these volatilization

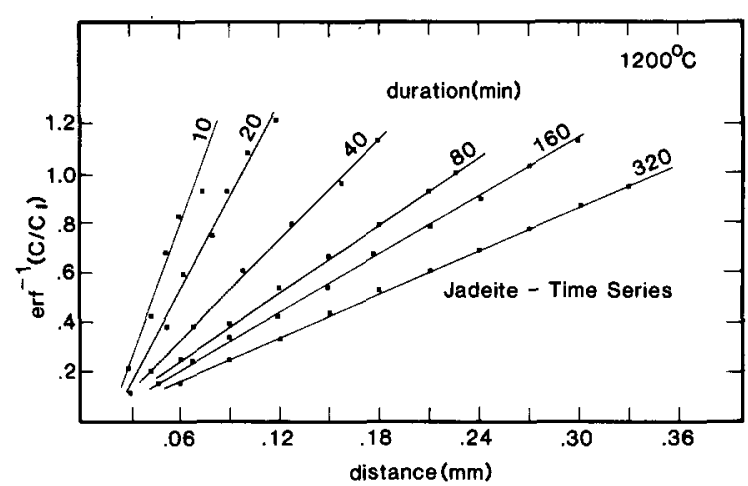

Fig. 2. Reduced concentration $\left(C / C_{1}\right)$ data for a time series of experiments on fluorine-bearing jadeite melt at $1200^{\circ} \mathrm{C}$.

experiments, $C_{0}=0$, because the gas phase is essentially pure $\mathrm{O}_{2}$ gas. Therefore the reduced concentration term for fluorine simplifies to $1-C / C_{1}$. The distance from the undepleted fluorine source is not measurable because it is a semi-infinite reservoir. Therefore, distance is measured from the undepleted oxygen source, i.e. the melt/gas interface. The relevant reduced concentration term is that for oxygen which, because $C_{\mathrm{F} \text { (reduced) }}+$ $C_{\mathrm{O} \text { (reduced) }}=1$, is equivalent to $C / C_{1}$. In the case of concentration-independent diffusion, the equation relating the diffusion coefficient $(D)$, distance from the undepleted oxygen source $(X)$ and time $(t)$ is as follows:

$$
X /(2 \sqrt{D t})=\operatorname{erf}^{-1}\left(C / C_{1}\right)
$$

where $\operatorname{erf}^{-1}$ is the inverse of the error function. In practice, plots of $\operatorname{erf}^{-1}\left(C / C_{1}\right)$ versus the distance from the melt-vapor interface yield straight lines whose slopes equal $1 / 2 \sqrt{D t}$. The linearity of such curves indicates that the diffusion process is concentration independent. Fig. 2 illustrates such plots for the time series of experiments on jadeite melt at $1200^{\circ} \mathrm{C}$.

\section{Results}

The experimental results are summarized in Table 2 and plotted versus reciprocal absolute temperature (Arrhenius plots) in Fig. 3. The temperature dependence of F-O interdiffusion may be 
TABLE 2

Experimental conditions and results

\begin{tabular}{lllll}
\hline $\begin{array}{l}\text { Composi- } \\
\text { tion }\end{array}$ & $\begin{array}{l}\text { Temper- } \\
\text { ature } \\
\left({ }^{\circ} \mathrm{C}\right)\end{array}$ & Duration & $\begin{array}{l}-\log _{10} D \\
\left(\mathrm{~cm}^{2} / \mathrm{s}\right)\end{array}$ & $\begin{array}{l}\text { Number } \\
\text { of experi- } \\
\text { ments }\end{array}$ \\
\hline Jadeite & 1200 & $600-19,200^{\mathrm{a}}$ & 7.62 & 7 \\
& 1300 & 3600 & 7.24 & 3 \\
& 1400 & 1860 & 7.01 & 3 \\
Albite & 1200 & 6900 & 8.98 & 3 \\
& 1300 & 7680 & 8.84 & 3 \\
& 1400 & 7200 & 8.46 & 3 \\
Peral- & 1200 & 11,280 & 8.50 & 3 \\
uminous & 1300 & 7560 & 7.98 & 3 \\
& 1400 & 7680 & 7.74 & 3 \\
\hline
\end{tabular}

a Results of a time series of seven experiments.

Uncertainty in $-\log _{10} D$ is estimated to be $\pm 0.1 \log$ units based on the standard deviation of the seven time series experiments in jadeite at $1200^{\circ} \mathrm{C}$.

fitted to Arrhenius equations of the form:

$\log _{10} D=\log _{10} D_{0}-E_{\mathrm{a}} / 2.303 R T$

where $D$ is the diffusivity at temperature $T(\mathrm{~K}), D_{0}$ is the pre-exponential or frequency factor, $R$ is the gas constant and $E_{\mathrm{a}}$ is termed the activation energy of $\mathrm{F}-\mathrm{O}$ interdiffusion. The Arrhenius parameters, $\log _{10} D_{0}$ and $E_{\mathrm{a}}$, for each melt are listed in Table 3.

The interdiffusion of fluorine and oxygen in the

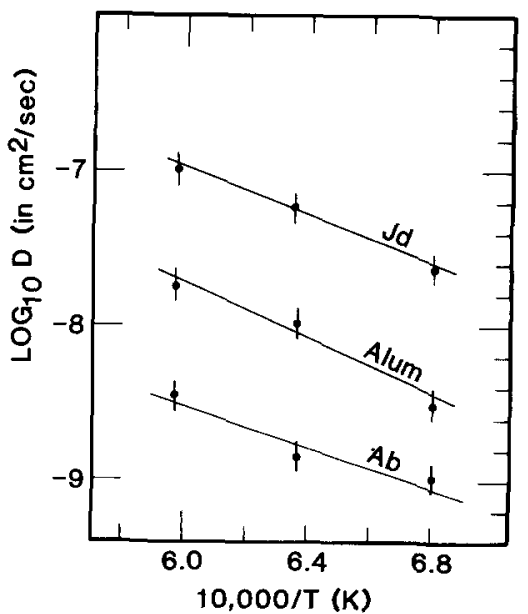

Fig. 3. Experimental data plotted as Arrhenius functions of temperature.
TABLE 3

Arrhenius parameters for 1 atm F-O interdiffusion

\begin{tabular}{lll}
\hline Composition & $\begin{array}{l}\log _{10} D_{0} \\
\left.\text { (in } \mathrm{cm}^{2} / \mathrm{s}\right)\end{array}$ & $\begin{array}{l}E_{\mathrm{a}}{ }^{*} \\
(\mathrm{kcal} / \mathrm{mole})\end{array}$ \\
\hline Albite & $-4.74 \pm 1.24$ & $28.9 \pm 8.9$ \\
Jadeite & $-2.50 \pm 0.64$ & $34.4 \pm 3.4$ \\
Peraluminous & $-2.09 \pm 1.03$ & $43.0 \pm 7.4$ \\
\hline
\end{tabular}

a Uncertainties quoted at 1 standard deviation.

$\mathrm{Na}_{2} \mathrm{O}-\mathrm{Al}_{2} \mathrm{O}_{3}-\mathrm{SiO}_{2}$ system is strongly dependent on melt composition. At $1400^{\circ} \mathrm{C}, \mathrm{F}-\mathrm{O}$ interdiffusivity increases over an order of magnitude from albite melt $\left(\log _{10} D=-8.46\right)$ to jadeite melt $\left(\log _{10} D=-7.01\right)$, along the join $\mathrm{SiO}_{2}-\mathrm{NaAlO}_{2}$. $\mathrm{F}-\mathrm{O}$ interdiffusivity also varies strongly with alkali/aluminum ratio. At $1200^{\circ} \mathrm{C}$ and 75 mole \% $\mathrm{SiO}_{2}$, the diffusion of fluorine in albite melt is slower than in the peraluminous melt $\left(\log _{10} D=\right.$ $-7.74)$.

If the trend of decreasing diffusivity with increasing $\mathrm{SiO}_{2}$ content extends beyond albite along the $\mathrm{NaAlO}_{2}-\mathrm{SiO}_{2}$ join then the F-O interdiffusivity measured in albite melt may be taken as an upper limit on F-O interdiffusivity in more silicic melts like rhyolites.

\section{Discussion}

\subsection{Comparison with viscosity data}

The suggestion that similar mechanisms and species may control viscous flow and diffusion in silicate melts has led several investigators to examine the validity of the Stokes-Einstein equation which inversely relates viscosity and diffusivity [20-24]. It has been generally concluded that the Stokes-Einstein relationship is qualitatively invalid in relating viscosity and network-modifying cationic diffusivities in silicate melts [20-22,25-27]. However, for the case of oxygen self-diffusion, Shimizu and Kushiro [23] have stated that an inverse correlation between $\log D$ and $\log \eta$ is well-approximated by the Eyring form of the Stokes-Einstein equation. The success of any equation which inversely correlates viscosity and oxygen 
diffusivity strongly implies that the same structural unit and mechanism are involved in both transport processes. Dunn [27] has recently shown that $\mathrm{O}^{2-}$ is probably the dominant species involved in oxygen diffusion in basaltic melts and Shimizu and Kushiro [23] argue that the viscous flow of jadeite and diopside melts is controlled by the diffusion of individual $\mathrm{O}^{2-}$ units.

The conclusions of this study regarding the application of the Stokes-Einstein equation to F-O interdiffusivity are negative (Table 4). Qualitatively, we would expect this result because the viscosity of these melts is a strong function of fluorine content [28] while the F-O interdiffusivity is not.

\subsection{Pressure dependence of $F-O$ interdiffusion in jadeite melt}

The results of this study for jadeite melt are compared with the high-pressure data of Dingwell and Scarfe [17] in Fig. 4. F-O interdiffusivity clearly increases with pressure from 0.001 to 10 kbar, as does oxygen self-diffusivity [23]. The dashed lines are interpolations based on the assumption of a smoothly decreasing pressure dependence with increasing pressure. In fact, Dunn [27] has shown that the pressure dependence of oxygen chemical diffusivity in basaltic melts is discontinuous in the pressure range of 1-10 kbar whereas Shimizu and Kushiro [23] show a smoothly increasing self-diffusivity of oxygen in jadeite melt in the pressure range of 5-20 kbars. This contrast

\section{TABLE 4}

Diffusivities + viscosities from 1200 to $1400^{\circ} \mathrm{C}$

\begin{tabular}{llll}
\hline & & $\log _{10} D$ & $\log _{10} \eta^{\mathrm{a}}$ \\
\hline Albite & 1200 & -8.98 & 4.25 \\
& 1300 & -8.84 & 3.84 \\
\multirow{3}{*}{ Jadeite } & 1400 & -8.46 & 3.46 \\
& 1200 & -7.62 & 4.21 \\
& 1300 & -7.24 & 3.73 \\
Peraluminous & 1400 & -7.07 & 3.29 \\
& 1200 & -8.80 & 5.28 \\
& 1300 & -7.98 & 4.68 \\
& 1400 & -7.74 & 4.09 \\
\hline
\end{tabular}

${ }^{a}$ Data from Dingwell et al. [28], $\pm 5 \%$.

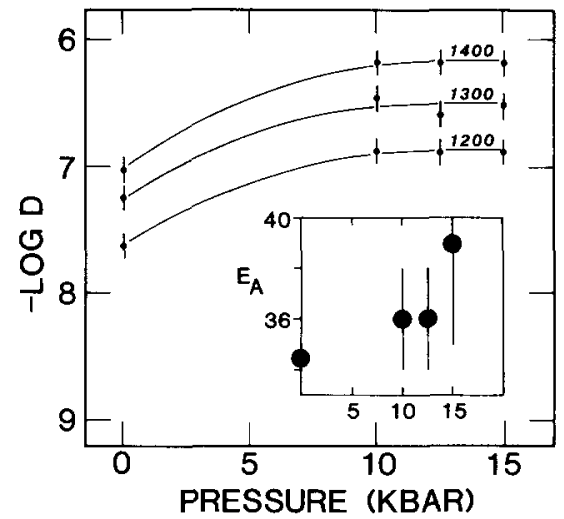

Fig. 4. Pressure dependence of F-O interdiffusivity in fluorinebearing jadeite melt (data from [17] and this study; inset: activation energy as a function of pressure).

in pressure dependence may result, in part, from comparison of chemical and self-diffusivity. Here we only wish to note that the F-O interdiffusivity increases from $1 \mathrm{~atm}$ to lower crustal pressures.

\subsection{Comparison with water}

The comparison of the chemical diffusion of fluorine and water is of interest for at least two reasons. Firstly, because of the geological significance of fluorine in igneous melts. It is clear that relatively dry, fluorine-rich silicate melts do occur [1-5] and their kinetic behavior deserves investigation and comparison with that of wet melts. Secondly, the structural comparison of fluorine and water may yield information on the speciation of these depolymerizing agents in silicate melts.

Chemical diffusion of water in natural silicate melts has been investigated by several workers [19,29-32]. In Fig. 5 the data for the chemical diffusion of fluorine in albite melt are compared with data for the chemical diffusion of water in obsidian melts [21]. Although the comparison of data in Fig. 5 involves melts of albite and obsidian composition, both represent relatively polymerized melts with alkali/aluminum ratios at or near $1: 1$.

The chemical diffusivity of fluorine in albite melt is approximately two orders of magnitude less than that of water in obsidian melt. Considering the composition dependence of fluorine diffusivity which is observed between jadeite and albite 


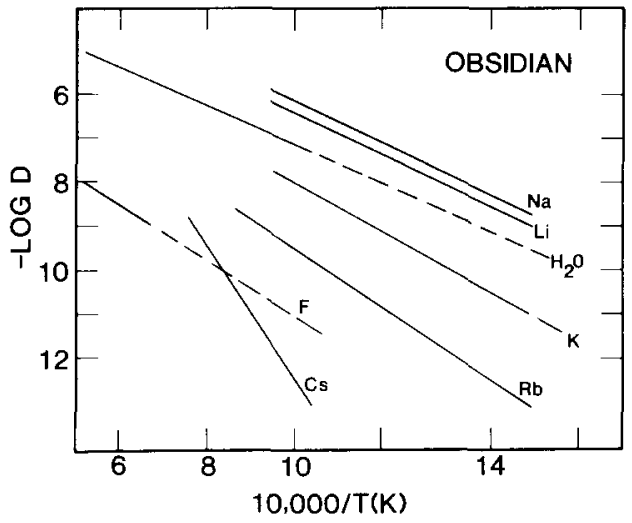

Fig. 5. Comparison of the chemical diffusivities of fluorine in albite melt and water in obsidian/rhyolite melt with tracer diffusivities of alkalies in obsidian melt (data from $[22,32]$ and this study).

melts (Fig. 3), the difference between fluorine and water diffusivity in obsidian melt is probably even larger than indicated in Fig. 5 . We believe that such a difference in the magnitude of diffusivity results from different diffusion mechanisms for fluorine and water in these melts.

Qualitatively, the difference in diffusivity leads us to infer that if $\mathrm{F}^{-}$is the principal diffusing species, as is suggested by the binary nature of the interdiffusion of fluorine and oxygen, then water is probably not transported principally as $\mathrm{OH}^{-}$, the monovalent anion of similar size. Conversely, if the diffusion of water is as $\mathrm{OH}^{-}$, then the species involved in fluorine diffusion would have to be a slower moving complex, perhaps $\mathrm{AlF}_{6}^{3-}$ [33]. Lack of cationic concentration gradients during $\mathrm{F}-\mathrm{O}$ interdiffusion leads us to favor the former possibility.

Perhaps the most significant difference between the diffusive behavior of fluorine and water is the concentration dependence of the chemical diffusion of water contrasted with the concentration independence of fluorine diffusion in all melts investigated in this study. The concentration dependence of water diffusivity in obsidian melt has been investigated by Delaney and Karsten [31] who state that the activation energy of chemical diffusion of water in obsidian melt remains constant while the frequency factor $\left(\log D_{0}\right)$ increases with water concentration. Delaney and Karsten
[31] propose that the concentration dependence of water diffusivity results from the occurrence of more than one solution site for water in obsidian melt whose relative occupancies change with water concentration. The concentration independence of fluorine diffusion suggests that one melt structural site is adequate to explain the observed diffusive behavior of fluorine.

\subsection{Diffusion mechanisms}

From a comparison of data on viscosities of and diffusivities in $\mathrm{F}$ - and $\mathrm{H}_{2} \mathrm{O}$-bearing melts ([28] and this study), it is apparent that the effects of fluorine and water on melt viscosity are similar while their diffusivities are considerably different. The viscosity data suggests similar structural roles for fluorine and water within polymerized silicate melts, probably the replacement of $\mathrm{Si}-\mathrm{O}-(\mathrm{Si}, \mathrm{Al})$ bridges with $(\mathrm{Si}, \mathrm{Al})-\mathrm{F}$ and $(\mathrm{Si}, \mathrm{Al})-\mathrm{OH}$, respectively. The diffusivity data, in contrast, highlight several differences in the transport of fluorine and water in these melts. Fluorine exchanges with oxygen via a mechanism which is independent of concentration and strongly dependent on melt composition. The exchange can be modelled as binary, without the involvement of any cations. Water, in contrast, diffuses in polymerized melts at a rate that varies with water concentration. Karsten et al. [32] have reported evidence of $\mathbf{K}$ and possibly Na concentration gradients produced during the chemical diffusion of water. These alkali concentration gradients suggest that interaction of water and alkalies may be an essential feature of chemical diffusion of water in these melts. The albite- $\mathrm{H}_{2} \mathrm{O}$ solubility model of Burnham [34] does imply that the solution of water in albite melt will involve alkali transport.

Fig. 5 presents tracer diffusion data for $\mathrm{Li}, \mathrm{Na}$, $\mathrm{K}, \mathrm{Rb}$ and $\mathrm{Cs}[22]$ and chemical diffusion data for water [21, fig. 5] in obsidian melts, as well as chemical diffusion data for fluorine in albite melt (this study). The diffusivity of alkalies in obsidian melt increases smoothly with decreasing ionic radius from $\mathrm{Cs}$ to $\mathrm{Na}$. However, $\mathrm{Li}$ diffuses at essentially the same rate as Na. In Fig. 5 it is evident that the chemical diffusivity of water, unlike that of fluorine, is very similar to the tracer 
diffusivity of $\mathrm{Na}$ (and Li). Perhaps the diffusion of hydrogen-bearing species in obsidian is controlled by the mobility of $\mathrm{Na}$ via an alkali exchange reaction similar to that discussed by Lanford et al. [35].

\section{Summary}

The 1 atm volatilization of fluorine from albite, jadeite and peraluminous melts in the system $\mathrm{Na}_{2} \mathrm{O}-\mathrm{Al}_{2} \mathrm{O}_{3}-\mathrm{SiO}_{2}$ involves (1) fluorine-oxygen interdiffusion to the melt surface, and (2) liberation of Si-F-bearing gas(es) from the melt surface. The $\mathrm{F}-\mathrm{O}$ interdiffusion is a binary, concentration-independent process which is strongly dependent on melt composition. Fluorine chemical diffusivity in jadeite melt increases from 0.001 to $10 \mathrm{kbar}$ while the activation energy remains unchanged. There is no reciprocal relationship between F-O interdiffusivity and melt viscosity. The relative magnitudes of the chemical diffusivities of fluorine and water suggest that these components diffuse by fundamentally different mechanisms. The diffusion of fluorine is a simple anionic exchange with oxygen whereas the diffusion of water probably involves alkali cations.

\section{Acknowledgements}

We wish to thank Steve Launspach for assistance with electron microprobe operation and data reduction and John Duke for providing neutron activation analyses of fluorine in the starting materials. We thank E. Bruce Watson and an anonymous reviewer for their constructive comments. This is University of Alberta Experimental Petrology Contribution No. 104.

\section{References}

1 J.C. Bailey, Fluorine in granitic rocks and melts: a review, Chem. Geol. 19, 1-42, 1977.

2 E.H. Christiansen, D.M. Burt, M.F. Sheridan and R.T. Wilson, The petrogenesis of topaz rhyolites from the western United States, Contrib. Mineral. Petrol. 83, 16-30, 1983.
3 P.J. Eadington and B. Nashar, Evidence for the magmatic origin of quartz topaz rocks from the New England batholith, Contrib. Mineral. Petrol. 67, 433-438, 1978.

4 V.I. Kovalenko, Distribution of fluorine in a quartz keratophyre dyke (ongonite) and solubility of fluorine in granitic melts, Geochem. Int. 10, 41-49, 1967.

5 N.B.W. Harris and G.F. Marriner, Geochemistry and petrogenesis of a peralkaline granite complex from the Midian Mountains, Saudi Arabia, Lithos 13, 325-337, 1980.

6 D. Kumar, R.G. Ward and D.J. Williams, Effect of fluorides on silicates and phosphates, Disc. Farad. Soc., 32, 147-154, 1961.

7 D.F. Barlow, Volatilisation of fluorides, borates and arsenic from glass, 11 th Int. Congr. Glass, Brussels, Chapter 19, 1-42, 1965.

8 J.A.M. Al-Dulaimy, A study of volatilisation from fluoride opal melts, unpubl. M. Tech. Sci. Thesis, Sheffield, 1978.

9 L.N. Kogarko, L.D. Krigman and N.S. Shardilo, Experimental investigations of the effect of alkalinity on the separation of fluorine into the gas phase, Geochem. Int. 9, 34-40, 1968.

10 V.K. Hunnold and R. Bruckner, Physikalische Eigenschaften und Struktureller Feinbau von Natrium-Aluminosilicatglasern und schmelzen, Glastech. Ber. 53, 149-161, 1979.

11 M. Taylor and G.E. Brown, Structure of mineral glasses, I. The feldspar glasses $\mathrm{NaAlSi}_{3} \mathrm{O}_{8}, \mathrm{KAISi}_{3} \mathrm{O}_{8}, \mathrm{CaAl}_{2} \mathrm{Si}_{2} \mathrm{O}_{8}$, Geochim. Cosmochim. Acta 43, 61-77, 1979.

12 A. Navrotsky, G. Peraudeau, P. McMillan and J.-P. Coutures, A thermochemical study of glasses and crystals along the joins silica-calcium aluminate and silica-sodium aluminate, Geochim.Cosmochim. Acta 46, 2039-2047, 1982.

13 F. Seifert, B.O. Mysen and D. Virgo, Three-dimensional network structure of quenched melts (glass) in the systems $\mathrm{SiO}_{2}-\mathrm{NaAlO}_{2}, \mathrm{SiO}_{2}-\mathrm{CaAl}_{2} \mathrm{O}_{4}$ and $\mathrm{SiO}_{2}-\mathrm{MgAl}_{2} \mathrm{O}_{4}, \mathrm{Am}$. Mineral. 67, 696-717, 1982.

14 E.F. Riebling, Structure of sodium aluminosilicate melts containing at least 50 mole $\%$ silica at $1500^{\circ} \mathrm{C}, \mathrm{J}$. Phys. Chem. 44, 2857-2865, 1966.

15 D.G.W. Smith and C.M. Gold, EDATA2: a FORTRAN IV computer program for processing wavelength and/or energy-dispersive electron microprobe analyses, in: D. Newbury, ed., Microprobe Anal. Soc. Proc., 14th Annu. Conf., San Antonio, pp. 273-278, 1979.

16 W.L. Bond, Making small spheres, Rev. Sci. Instrum. 22, 344-345, 1951.

17 D.B. Dingwell and C.M. Scarfe, Chemical diffusion of fluorine in jadeite melt at high pressure, Geochim. Cosmochim. Acta 48, 2517-2525, 1984.

18 J. Crank, The Mathematics of Diffusion, 2nd ed., Oxford University Press, 1975.

19 H.R. Shaw, Diffusion of $\mathbf{H}_{2} \mathrm{O}$ in granitic liquids, I. Experimental data, in: Geochemical Transport and Kinetics, A.W. Hofmann, B.J. Giletti, H.S. Yoder, Jr. and R.A. Yund, eds., Carnegie Inst. Washington Publ. 634, 139-154, 1974.

20 E.B. Watson, Calcium diffusion in a simple silicate melt to 30 kbar, Geochim. Cosmochim. Acta 43, 313-322, 1979.

21 A.W. Hofmann, Diffusion in natural silicate melts: a criti- 
cal review, in: Physics of Magmatic Processes, R.B. Hargraves, ed., pp. 385-415, Princeton University Press, 1980.

22 A. Jambon, Tracer diffusion in granitic melts: experimental results for $\mathrm{Na}, \mathrm{K}, \mathrm{Rb}, \mathrm{Cs}, \mathrm{Ca}, \mathrm{Sr}, \mathrm{Ba}, \mathrm{Ce}, \mathrm{Eu}$ to $1300^{\circ} \mathrm{C}$ and a model of calculation, J. Geophys. Res. 87, 10797-10810, 1982.

23 N. Shimizu and I. Kushiro, Diffusivity of oxygen in jadeite and diopside melts at high pressures, Geochim. Cosmochim. Acta 48, 1295-1304, 1984.

24 P. Winchell and J.H. Norman, A study of the diffusion of radioactive nuclides in molten silicates at high temperatures, High Temp. Tech. 3rd Int. Symp. Asilomar, pp. 479-492, 1967.

25 M. Magaritz and A.W. Hofmann, Diffusion of Sr, Ba and $\mathrm{Na}$ in obsidian, Geochim. Cosmochim. Acta 42, 595-605, 1978.

26 C.A. Angell, P. Cheeseman and S. Tamaddon, Water-like transport anomalies in liquid silicates investigated at high $T$ and $P$ by computer simulation techniques, Bull. Mineral. 106, 87-97, 1983.

$27 \mathrm{~T}$. Dunn, Oxygen chemical diffusion in three basaltic liquids at elevated temperatures and pressures, Geochim. Cosmochim. Acta 47, 1923-1930, 1983.

28 D.B. Dingwell, C.M. Scarfe and D.J. Cronin, The effect of fluorine on viscosities in the system $\mathrm{Na}_{2} \mathrm{O}-\mathrm{Al}_{2} \mathrm{O}_{3}-\mathrm{SiO}_{2}$ : implications for phonolites, trachytes and rhyolites, Am. Mineral. (in press).

29 I. Friedman and W. Long, Hydration rate of obsidian, Science 191, 347-352.

30 A.A. Arzi, Fusion kinetics, water pressure, water diffusion and electrical conductivity in melting rock, interrelated, $J$. Petrol. 19, 153-169, 1978.

31 J.R. Delaney and J.L. Karsten, Ion microprobe studies of water in silicate melts: concentration-dependent diffusion in obsidian, Earth Planet. Sci. Lett. 52, 191-202, 1981.

32 J.L. Karsten, J.R. Holloway and J.R. Delaney, Ion microprobe studies of water in silicate melts: temperature-dependent water diffusion in obsidian, Earth Planet. Sci. Lett. $59,420-428,1982$.

33 D.A.C. Manning, D.L. Hamilton, C.M.B. Henderson and M.J. Dempsey, The probable occurrence of interstitial aluminum in hydrous fluorine-bearing and fluorine free melts, Contrib. Mineral. Petrol. 75, 257-262, 1980.

34 C. Wayne Burnham, Water and magmas: a mixing model. Geochim. Cosmochim. Acta 39, 1077-1084, 1975.

35 W.A. Lanford, K. Davis, P. Lamarche, T. Laursen, R. Groleau and R.H. Doremus, Hydration of soda-lime glass, J. Non-Cryst. Sol. 33, 249-266, 1979. 